\title{
VII. On the preparation of amber varnish, and the application of it to different kinds of stained wood
}

\section{Nils Nyström}

To cite this article: Nils Nyström (1800) VII. On the preparation of amber varnish, and the application of it to different kinds of stained wood, Philosophical Magazine Series 1, 7:27, 232-239, DOI: $10.1080 / 14786440008562580$

To link to this article: http://dx.doi.org/10.1080/14786440008562580

曲 Published online: 18 May 2009.

Submit your article to this journal \lceil

Џ Article views: 2

Q View related articles 
this precaution, the laft fpirit of wine that paffes over would be rendered impure by more or lefs water.

In common, corn fpirit has an unpleafant fimell and tafte, the primary caufe of which is carelefs management of the fire during the firft diftllation as well as during the rectification; as by thefe means, in the firf diftilation in particular, the grains readily become burnt, and confequently communicate that tafte and fmell to the ditilited liquor. The decompolition of the gelatinous matter of the grain feems alfo to contribute to this defect. The addition of lixivious falts, chalk, or charcoal, during the rectification, is the beft means to improve fpirits which have been hurt in this manner.

I am however of opinion, that it is pofible to preferve the corn fpirit in a perfect ftate during the firft diftillation. The fault generally lies in the fermentation of the wafh being too long continued. In general, the diftillation is not begun till the fermenting liquor throws up no more bubbles, and thows itfelf perfectly tranfparent under the fcum: but it has been confirmed by feveral experiments, that the corn fpirit is obtained ftrongeft, and in the greateft abundance, when the mixture is fubjected to diftillation in its higheft degree of fermentation. If the fermentation be fuffered to obtain its utmoft term completely, a quantity of vinegar will be formed, which not only contributes great deal to give the liquor an unpleafant tafte, but actually occafions a confiderable lofs of the faccharine matter neceffary for the production of fpirit of wine.

VII. On the Preparation of Amber Varnifb, and the Application of it to different Kinds of fained Wood. By Nrus Nxström, Apotbecary of Norrköping *. As furniture of foreign wobd is in general expenfive, the
ufe of the indigenous kinds of wood ought not to be neglected,
efpecially when they are of a compact texture, have a fine
grain, and are futficiently hard. Furniture made of thefe
From the Tranfactions of the Academy of sciences at Stockbolm for the
179.\%. 
kinds of wood, after it has been well polifhed, may be fained of different colours, and then done over with linfeed oil and amber varnifh.

As my principal view, however, was to try in what manner different kinds of wood could be ftained fo as to retain their colour longeft, and in what manner mahogany could be beft imitated, I applied fuch a compofition as I thought would beft anfwer the purpole on the twelve following kinds of wood; viz. elm, oak, red and white beech, maple, pear-tree, wild hawthorn, white beam-tree, afh, alder, birch, and pine. Of thefe, the maple, birch, alder, and white beech, when ftained with a folution of iron, had the greateft refemblance to mahogany. The appearance of the other kinds was various, according to the diverfity of their colour and veins, and according as they were more or lefs porous, and imbibed a greater or lefs quantity of the ftain.

The amber varnith prepared in different places is not always of equal goodnefs. This is owing to two caufes: $x$ ft, The carelefs manner in which the amber is melted; $2 \mathrm{~d}$, Becaufe the linfeed oil, being ton much or too little boiled, acquires, in a greater or lefs degree, a drying property. A proof of amber varnith being good, is, if, when applied on any article in an apartment of the common temperature, it becomes dry within from twelve to twenty-four hours.

By the experiments which I made, I have found that the following procefs for preparing it is the beft:-Put pounded and fifted amber into a pan of caft iron with a flat bottom, and let the amber be fpread out at moft to the thicknefs of an inch. Place the pan in an upright pofition over an uniform coal fire, and let it remain till the amber fufes and becomes liquid; then pour it out on a cold plate of copper or iron. When the amber has cooled, break it into pieces; and if it has a bright blackifh-brown appearance on the fracture, and weighs about one-half of what it did before being melted, you may be certain that it is proper for the intended purpofe. Particular attention muft be paid to this circumftance; for, if the amber is fufed too little, fo that part Vos. VII. $\mathrm{Hh}$ 
of it remains unmelted, it will not be diffolved by the varnifh; and if the operation be performed with a continued and frong heat, it will be burnt and unfit for ufe.

When the amber is kept over a weak fire it will not melt, but becomes a fort of blackih brown incruftation, which alfo may be employed for varnith provided it has not: been too much or too little evaporated : it will be in the beft condition when you obtain half a pound from a pound. If the amber is too little evaporated, it mult be again put into the pan till it be reduced to the proper weight. The fame thing is to be obferved when you melt it ; but the parts which are not fufed mult be picked out, in order to be afterwards alfo melted.

I have found that a pan with a flat bottom is better than one with a round bottom, becaufe the melting or evaporation is effected fooner in the former than in the latter; for in the latter the amber lies thick in the middle, and is burnt at the bottom and fides before it can be brought to melt or evaporate.

It is not neceffary, for making varnifh, to pick out pure and tranfparent amber, but only the common yellow fmall fragments, which may be procured for half the price of that in lumps. The earthy part, which is found in amber not of the clearef kind, feparates itfelf from the warm varnith when it is fuffered to ftand fome time before it is decanted.

\section{Metbod of preparing Linfeed-Oil VarnißB.}

One pound of well pulverifed and fifted litharge, four ounces of finely pounded white vitriol, and one quart of linfeed oil. Put thefe ingredients into an iron pan of fuch a fize that it may be only half full; mix them well together, and boil them till all the moifture is evaporated, which may be known. by a pellicle being formed on the furface, or by the barrel of a quill burfting when thruft to the bottom of the boiling varnifh. Then take it from the fire and pour off the clear liquid, taking care to keep back the thick part which has depofited itfelf at the bottom, While boiling, it muft be firred feveral times round, that the litharge may not fall to the bottom; but you muft not ftir it conftantly, elfe fuperfluous 
litharge would be diffolved, and the varnifh become too thick.

The compofition of amber varnifh confifts of half a pound of melted or roafted amber, one pound and a half of linfeedoil varnifh, and two pounds of turpentine oil. The amber and linfeed-oil varnifh are to be mixed together in a deep caft-iron pan, of fuch a fize as to be only one-third full, and to be kept over a llow fire till the amber is diffolved, which may be known by its fwelling up: the operator, therefore, muft have at hand a large copper or iron veffel, that the varnifh may be held over it in cafe it thould rife above the fides of the pan, and to prevent the lofs that would thereby be occafioned. When the varnifh is diffolved; the pan mult be taken from the fire; and when the mixture has cooled, the turpentine oil is to be poured into it, continually ftirring it. Then let it ftand fome time, that the coarfe undiffolved particles may depofit themfelves at the bottom; after which pour off the clear varnifh, and, having ftrained it through a piece of linen, put it into bottles for ufe.

In boiling the varnifh, care muft be taken that it may not boil over or catch fire. Should this happen to be the cafe, it muft not be extinguifhed by water; for this mode would occafion fuch a fputtering, that the operator would be in danger of having his face befpattered with the boiling varnith. The beft method, therefore, is to cover the veffel in fuch a manner as to exclude the air, and with any thing that may be at hand, fuch as a piece of wood, plate of iron, or any thing elfe that may cover the veffel and extinguifh the flame.

\section{Iron Stain.}

Eight ounces of iron-filings and thirty-two ounces of common aquafortis. The aquafortis muft firt be mixed with fixteen ounces of water in a ftone jar, and then a few of the filings are to be added, and well ftirred round with an iron or wooden fpatula. This preparation muft be made in a chimney, becaufe the folution is attended with heat, effervefcence, and the difengagement of noxious vapours: it is of importance, alfo, that the jar thould be of fuch a fize as to prevent the matter from running over. After the greater part H $\mathrm{h} 2$ 
of the iron has been diffolved in this manner, the folution will be of a yellowith brown colour. As foon as the mixture has cooled, pour it into a bottle placed in a pan, and let it ftand a day or two, without being corked, over a warm ftove; during which time thake the bottle frequently. The bottle being then fuffered to cool, pour into it one pound three quarters of river water, ftirring it well round, and leave it at reft for a few minutes till the undiffolved part finks to the bottom: then pour the folution into another bottle, and cork it up for ufe.

When this preparation has been carefully made according to the above directions, you obtain a yellowin brown folution, which may be employed for ftaining. In cafe too much water, however, has been at firft employed, or too weak aquafortis, the colour becomes dark brown; and therefore the addition of the aquafortis muft be increafed in that proportion which the folution requires, obferving the abore rules.

This ftain may be applied to all kinds of wood except oak, which contains too much aftringent matter, and therefore on the firft application becomes almoft black. It communicates to the various kinds of wood different colours, according as it is applied in greater or lefs quanitity; fuch as yellow, yellowifh brown, and dark brown, with reddifh brown ftripes or fpots.

As far as I have been able to afcertain by experience, this ftain is one of the moft durable; it withftands the air and rays of the fun without changing its colour. I have fpecimens of it which have been expofed four years continually to the fun and air, without their colour being altered.

\section{Brazil Wood Stain.}

Eight ounces of real Brazil wood, four ounces of alum, and four ounces of finely pounded reddle or red ochre. Pour over this mixture a proper quantity of water; and, having fuffered it to remain in that ftate twenty-four hours, boil it to a fourth part; then ftrain it through a piece of linen cloth, and preferve it in a glafs bottle for ufe.

If one pound of the ftain No. 1 . be diluted with three pounds of water, immerfe fome pieces of wood in it, and 
depofit the whole in a warm place: the wood will imbibe the liquid to the depth of a quarter of an inch, and in the toft parts of the wood it will penetrate ftill further.

It muft however be remarked, that the ftaining liquor muft be diluted with a greater or lefs quantity of water, according as the wood is darker or whiter, more or lefs aftringent. The wood muft often be turned, and care mult be taken that it may acquire an uniform and proper colour; after which it may be taken out and dried.

The like procefs muft be followed when the ftain No. 2. is employed, only that the fame attention is not neceffary in regard to obtaining an uniformity of colour. This mode, however, can be ufed only on a fmall fcale.

\section{Metbod of faining Articles of White Wood witb the above Compounds.}

Rub the ftain No. $x$. over the wood with a piece of fponge five or fix times till it acquire a proper mahogany colour. While the liquor is applied, fhake it or ftir it carefully round, that the iron ochre, which has depofited itfelf at the bottom, may be well mixed with the ferruginous folution that ftands over it; and between each application of the liquid the wood muft be fuffered to become thoroughly dry. After this, it muft be rubbed over once or twice with linfeed oil, letting it dry before the oil is applied the fecond time. The more the wood is foaked with linfeed oil, fo much the better; as in that cale it does not imbibe fo much of the amber varnifh, which only depofits itfelf on the furface, and gives it a bright appearance.

When the wood has been thus rubbed over, and well dried, the amber varnith mult be applied in an uniform manner with a fponge once or twice, or until it acquires a fmooth fhining furface. If the wood has been well done over with linfeed oil, one application of the varnith only will be neceffary; but on bedfteads, chefts of drawers, chairs and other furniture which are expofed to more ufe, it muft be applied feveral times, and each time they muft be well dried.

After the application of the varnifh, if any inequalities or lumps appear, they may be removed, after the article is dry, 
by means of a carpenter's rufh, and a frefh coating of tarniff applied to the place. For applying the varnifh, I have found it moft convenient to ufe a fponge; as by thefe means it can be laid on in a nuch more uniform manner than by a painter's bruth, which, for the moft part, leaves ftripes or loofe hairs behind it. The fponge with which the varnifh is laid on, muft, between each application, be well fhut up in a wide-mouthed bottle, that the varnifh it has imbibed may not be dried by the air, which would render it hard, and unfit for ufe.

The fame procefs is to be followed with the ftain No. 2o When applied to knotty birch wood or alder, the wood becomes undulated, becaufe the liquor extends itfelf more crofswife. The cafe is the fame with fat and knotty pine wood or fir; for the refinous fpots do not fo ftrongly attract the ftain as the other parts. This, however, makes the appearance of the wood not difagreeable.

The amber varnith may be applied alfo over almoft all oil colours except blue, which it would change to green. It is attended with this advantage, that it never cracks; as is the cafe in general with lack varnifhes, and thofe prepared with fpirit of wine.

I have found, alfo, that this varnith is proper for being applied on real gilding, becaufe it makes no perceptible alteration in the colour; efpecially when laid on thin, and in an uniform manner. This object alfo is obtained, that the gilding may be cleaned by means of fpirit of wine, or of foap and water, without fuftaining any injury. For falfe gilding, however, it is improper; as it attacks it, and makes it rufty and green.

I have applied this varnifh, in the above manner, to bedpofts, drawers, tables, and chairs, which at the end of two years were little or nothing changed in their appearance. When this varnifh has become perfectly dry and hard, it withftands boiling heat and friction; and does not lofe its fplendour by the courfe of time, unlefs rubbed or fcoured with fand. It prevents ink, or any other coloured liquid that may be fpilt on furniture, from penetrating into the wood, and caufes ftains to be eafily removed by walhing with water. 
On this account, it is very proper for being applied on articles of mahogany. It renders the foft kinds of wood much harder at the furface.

This varnith ufed in this manner would not be expenfive, as eight ounces of it is fufficient for a common card-table. Should the table be fcratched, the injured part may be eafily repaired by a new coating of varnih; and if it be new varnifhed every four or five years, it will always retain a beautiful and bright appearance.

Tables and other flat articles which reguire a great deal of polifhing, when the ftain and linfeed oil have been applied, may be rubbed with a piece of pumice tone before they are done over with the varnith. This pumice ftone mult be made flat on one fide, and mut be free from fand, fo as not to feratch the wood. As the fofter kinds of wood fwell up, for the moft part, when the ftain is applied, and lofe their fmoothnefs; rubbing them in the above manner with pumice ftone is the more neceffary.

VII. Comparative View of fome dangerous Difeafes, fuppofed to be occafioned by Infects, wbich prevail in Sweden, Ruffia, siberia, and the adjacent Countries.

[Concluded fiom $\mathrm{Pa}_{5}$ e $14+$. ]

T HE late Dr. J. J. Lerche, of Peterfburgh, communicated to me the following account of fome petilential dif: eafes which manifeft themfelves in the marthy diftricts around that city and in other places during dry fummers, and which appear to me to be of the fame nature as the Siberian difeafe before mentioned. But that $I$ may not be accufed of endeavouring to pervert facts for the purpofe of fupporting my own opinions, I fhall here give the author's own words :

"In the year 1756 , a very hot dry fummer, unhealthful for men as well as cattle, took place after a very unhealthful winter. The difeafe which then prevailed continued till the harveft, and extended on one fide to Mofcow, and on the other to Livonia and through Finland. As foon as the fenate anse informed of it, Condoide, phyfician to the court, was ordered 